I.U.D.s, such as those releasing progestogens, copper ions, or any other potential antiimplantation agent.-We are, etc.,

MaX Elstein University of Southampton KAREN FERRER

1 Medel, M., et al., Paper delivered at Family Planning Research Conference at Exeter, September 1971 .

Hagenfeldt, $\dot{K}$., Plantin, L. O., and Diczfalusy, E., Acta Endocrinologica, 1970, 65, 541.

Janick, J., Zeitz, L., and Whitmore, W. F., Fertility and Sterility, 1971, 22, 573 .

fournal of Mitchell, R. F., and Syrett, J. T., British Commonwealth, 1971, 78, 180.

SIR,-It is refreshing to see interest in the mechanism of action of the intrauterine contraceptive device and its potential hazards expressed in Dr. D. Wolfers's letter (8 January, p. 112). However, his concern about impregnated I.U.D.s and his representation of inert I.U.D.s such as the Dalkon shield as an end point in development requires comment. His example of the Dalkon shield as an "unimpregnated" device is unfortunate, since it contains over $40 \%$ of its weight as barium sulphate.

The use of, albeit, more noble metals than copper in I.U.D.s in the first half of this century was never shown to cause any increase in the incidence of malignancy in the male and female genital tracts. The manufacture of some "unimpregnated" I.U.D.s allows the formation of ridges on which cells can lodge and persist beyond their normal cycle, ${ }^{1}$ a situation analogous to the known carcinogenic effect of explantation.

The relation between the area of endometrium in contact with the I.U.D. and its effectiveness may be more subtle than Dr. Wolfers's letter would imply. There is evidence that "inert" I.U.D.s can not only stimulate uterine macrophages to attack the conceptus $^{2}$ but can also stimulate an increased circulating immunoglobulin concentration. ${ }^{3}-\mathrm{I}$ am, etc.,

R. M. Pearson

Royal Postgraduate Medical School,

Hammersmith Hospital,

London W.12 Potts, M., and Pearson, R. M., Fournal of
Obstetrics and Gynaecology of the British Commonwealth, 1967, 74, 129 .

2 Sagiroglu, N., and Sagiroglu, E., American fournal of Obstetrics and Gynecology, 1970, 106, 506.

3 Holub, W. R., Reyner, F. C., and Forman G. H., American fournal of Obstetrics and

** Dalkon (not Dalcon, as previously stated) is the correct spelling for the name of this contraceptive shield.-ED., B.M.f.

\section{Removal of Extrauterine Saf-T-Coil through Laparoscope}

SIR,-A 20-year-old nulliparous woman married for twelve months was referred to the hospital for contraceptive advice. She had previously been using the contraceptive pill but after three months' amenorrhoea from Anovlar 21 she was changed to Volidan 21 and after a further six months' amenorrhoea was referred to hospital. Prior to starting contraception she had a normal regular menstrual cycle. She was advised to discontinue the contraceptive pill and requested an intrauterine device. being strongly motivated against barrier methods of contraception.

Under general anaesthesia the vaginal findings were: normal vulva and vagina, retroverted small mobile uterus, and no abnormality was detected in the adnexae. The cervical os was healthy and dilated with ease to Hegar No. 7. The uterine sound was passed 4 in. $(10 \mathrm{~cm})$ and minimal curettings were obtained which showed mucus only on microscopy. A Saf-T-Coil 33.6 was inserted without difficulty.

The following morning she complained of tenderness over the lower abdomen but there was no rebound tenderness on palpatation; the vital signs were satisfactory but vaginal examination confirmed tenderness in the right fornix. The coil loops were not seen on speculum examination and the coil could not be felt with a uterine sound. $X$-ray showed the coil in the right iliac fossa. Examination and laparoscopy under general anaesthesia with endotracheal intubation were then undertaken.

At operation, the pelvic findings were as previously noted and no coil was found on curettage. Laparoscopy showed a perforation of the right uterine cornu which was no bleeding but old blood was noted in the pouch of Douglas. The Saf-T-Coil was lying on loops of bowel in the right iliac fossa and was removed without difficulty through a suprapubic incision, holding the stem of the Saf-T-Coil with the Palmer forceps. The patient recovered without complication and was discharged home 48 hours later.

Leventhal et al. ${ }^{1}$ describe laparoscopic removal of intrauterine contraceptive devices following uterine perforation. They recommend minimal Trendelenburg position to avoid the possibility of the device being displaced into the upper abdominal cavity. Their experience was of four Lippes loops, and this case would add support for laporoscopy as a suitable alternative to laparotomy should this complication arise.-We are, etc.

\section{R. S. LEDWARD C. HEALEY Ronald Eadis}

Royal Sussex County Hospital, Brighton, Sussex

$$
\begin{aligned}
& \text { Leventhal, J. M., Simon, L. R., and Shapiro, } \\
& \text { S. S., American fournal of Obstetrics and } \\
& \text { Gynecology, 1971, III, 102. }
\end{aligned}
$$

\section{Contact Dermatitis from Xerumenex}

SIR,-We would like to report a case of contact dermatitis from Xerumenex ear wax solvent.

A man aged 43 developed bilateral acute otitis externa with spread of the dermatitis to the face, neck, and upper chest. There was marked swelling of the eyelids. The day before the onset of the eruption he had instilled Xerumenex once into each ear. It had probably been left in overnight. The manufacturers suggest that Xerumenex should be flushed out of the ears 15-30 minutes after application.

Readings at 48 and 96 hours of 24 standard patch tests were negative. A patch test with one drop of Xerumenex gave a strong reaction $8 \mathrm{~cm}$ in diameter at 96 hours. Xerumenex is one of the protein-derived surfactants. The active ingredient is triethanolamine polypeptide oleate-condensate $10 \%$. The patient was also tested against the other inoredients of Xerumenex and against triethanolamine, which is a known skin sensitizer. ${ }^{1}$ There was a strong reaction to triethanolamine polypeptide oleate-condensate $1 \%$ and no reaction to chlorbutanol $1 \%$, propylene glycol $10 \%$, or to tri- ethanolamine $10 \%$. On routine patch testing of eight patients against Xerumenex three produced slight reactions and one a moderate reaction. Of six patients tested to $1 \%$ triethanolamine polypeptide oleate-condensate $1 \%$ one produced a minimal reaction.

We thank Mr. A. W. Morrison and Dr. Harvey Baker for permission to report this case and Dr. Etain Cronin for the triethanolamine.

-We are, etc.,

Dermatology and Ear Nose and C. I. JOHNSTONE
Throat Departments,
London Hospital,
London E.1
1 Fisher, A. A., Pascher, F., and Kanof, N. B.,
Archives of Dermatology, 1971, 104, 286.

\section{Ganglion Cysts of Bones}

SIR,-The structure and pathogenesis of ganglia occurring around joints described in your leading article entitled "Ganglion Cysts of Bones" (13 November 1971, p. 380) are inconsistent with our recent ultrastructural studies $^{1}$ on ganglia of the wrist. Your leading article refers to the suggestion of some workers ${ }^{23}$ that "there is first a proliferation of fibroblasts," yet cells acceptable as fibroblasts are virtually absent from the wall of ganglia of the wrist. It is also misleading to say that "The dense fibrous capsule encloses cysts containing a viscid, jelly-like fluid," for, though such a statement is of course justifiable on the grounds that the wall contains collagen fibres, it contains virtually no fibroblasts.

In discussing the pathogenesis of ganglia your leading article mentions, among others, a view that the ganglion originates from an out-pouching of synovial membrane through a defect in a joint capsule or a tendon sheath, and then states that this can seldom be substantiated by dissection but that possibly the original connexion underwent attenuation during the evolution of the lesion. One would expect that if ganglia did arise from synovial membrane they would be lined by synovial cells, but they are not.

Ultrastructurally synovial cells are quite characteristic, and indeed two types, designated $A$ and $B$, are now known to occur in the synovial intima of all species studied to date. ${ }^{4}$ Our studies show that ganglia of the wrist have no obvious cellular lining but occasionally cells or groups of cells do occur in this region. These cells, however, bear no resemblance whatsoever to synovial cells or fibroblasts. Almost all the cells in the wall of the ganglion and the occasional ones lying at the surface between wall and mucoid content resemble smooth muscle cells, for they contain numerous characteristic myofilaments along which typical focal densities can be frequently demonstrated. Variants of this cell type, which besides containing mvofilament also contain ahundant rough endoplasmic reticulum and Golgi complex. were also found in our study. The situation here is somewhat analogus to that seen in the arterial wall, where two light microscopists had believed that fibroblasts resided but electron microscopy has shown ${ }^{5}$ the presence of cells, called multifunctional mesenchvmal cells, containing mvofilaments and variahle amounts of rough endoplasmic reticulum and Golgi complexes. Indeed, the resemblance between the cells in ganglia and arterial wall is quite striking, and we believe that the cells resembling smooth muscle seen in the 
wall of ganglia are multifunctional mesenchymal cells capable of producing not only myofilaments but also collagen fibres and the interfibrillary mucopolysaccharide matrix.

The lining and contents of ganglia were also examined by electron microscopy. It was found that much of the ganglion wall does not have any cellular lining and that disintegrating collagen and necrotic debris lie at the surface. In segments where lining cells are found they appear to be degenerate rather than engaged in secretory activity. Thus the long-held notion that the ganglion cavity is lined by fibroblasts or synovial cells is not supported by our observations. Examination of the mucoid ganglion content also suggests that a degenerative rather than a secretory process is in operation, for abundant disintegrating collagen and fibrillary and cellular debris were seen lying in the mucoid matrix.

I believe that these ultrastructural findings substantially alter the basis of discussion on the pathogenesis of ganglia, but I am at a loss to suggest where these multifunctional mesenchymal cells come from and how the ganglion is produced. One could propose that they perhaps come from neighbouring vessels, or one could evoke the hypothesis of the intermutability of mesenchymal cells and suggest that pre-existing mesenchymal cells in this region (joint capsule) may alter to form the type of cell we have described. -I am, etc.,

Department of Pathology,

University of Saskatch

Un versity
Saskatoon,

Canada

1 Ghadially, F. N., and Mehta, P. N., Annals of

the Rheumatic Diseases, 1971 , 30, 31. Orthopaedics, 1969, 63, 184.

King, E. S. J., Australian and New Zealand fournal of Surgery, 1932, 1, 367 Ghadially, F. N., and Roy, S., Ultrastructure of Wissler, R. W., Circulation, 1967, 36, 1.

\section{Wandering Spleen with Complete Procidentia}

SIR,-Wandering spleen or movable spleen is a congenital anomaly which is commoner in women. The condition is very rare and it is exceptional to make the correct diagnosis in the first instance. ${ }^{1}$ Wandering spleen associated with complete procidentia must be extremely rare, and we wish to record a case.

A 50-year-old multiparous woman was admitted to the Department of Obstetrics and Gynaecology of Lady Reading Hospital, Peshawar on 19 March 1969. She had had a complete procidentia for two years, and had been aware of a swelling in the hypogastrium for 10 years, which was causing her no symptoms. Her menstrual cycle had been regular but heavy. There was no other relevant history. On examination she was thin and pale. Her pulse, temperature, and blood pressure were normal; cardiovascular and respiratory systems revealed no abnormality. On abdominal examination no mass was palpable nor was there any tenderness. Apart from complete procidentia with a few decubital ulcers on the anterior vaginal wall there were no abnormal findings.

A vaginal hysterectomy was carried out under spinal anaesthesia. While the bladder was being catheterized a tumour about 4 in $\times 3$ in $(10 \mathrm{~cm} \times 7.5 \mathrm{~cm})$ was noticed in the suprapubic region. It could also be felt on pelvic examination. This tumour was soft and freely mobile. A provisional diagnosis of ovarian cyst with complete procidentia was made. When the uterovesical pouch was opened the tumour came into view. It had a notch and was obviously the spleen. Both ovaries and Fallopian tubes were normal.

Vaginal hysterectomy was completed without any complication. It was followed by a laparotomy. The spleen was found lying in the pelvis having a pedicle which was 6 in $(15 \mathrm{~cm})$ long. Splenectomy was carried out.

The postoperative period was uneventful, and she was discharged on the tenth day. Six weeks later she was well and had no complaints.

Maingot $^{2}$ states that few surgeons have operated on ptosis of the spleen. Approximately 150 cases of wandering spleen and its complications have been recorded so far. ${ }^{3-6}$

Wandering spleen may either be congenital or acquired. In the former type, the ectopic position of the spleen may be due to absence of the supporting phrenicocolic ligament or due to excessive length of the splenic pedicle. The acquired causes may be the stretching and elongation of the anchoring peritoneal folds or suspensary ligaments, or due to increased weight of the spleen, or the conditions which bring about relaxation of abdominal wall and the ligaments which support the abdominal viscera. Any of these factors may be the determining one. It seems that the main causes of the prolapse of the uterus and spleen are very much alike-that is, a laxity of the ligaments due to repeated pregnancies.-We are, etc.,

ZaKia Minhas Lala RUKH MaLIK

Department of Obstetrics and Gynaecology,

Lady Reading Hospital,

1 Bailey, H., and Love, R. J. McNeill, A Shor Practice of Surgery, 11th edn., p. 372, London Lewis, 1959

2 Maingot, R., Lancet, 1952, 1, 625.

3 Abell, I., Annals of Surgery, 1933, 98, 722. Pearson,', J. B., British fournal of Surgery, 1964 $51,393$.

Anand, S. V., and Davey, W. W., British foumal of Surgery, 1965, 52. 339.
Simpson, A., and Ashby, E., British fournal
of Surgery, 1965, 52, 344.

\section{Rumination}

SIR,-We were interested to read your leading article on rumination in infancy (2 October 1971, p. 3) and the association with oesophageal hiatus hernia. We would like to draw attention to an occurrence in an adult male.

In 1970 a 67-year-old farmer was admitted with a history of 25 years' variable digestive disorder and two mild attacks of haematemesis and melaena. For the past 12 years vomiting and loss of weight had been the outstanding complaints, worse at times of mental stress. Vomiting of up to one pint $(0.61$.) was seen to be effortless, apparently not self-induced, and not followed by remastication or reswallowing of any vomitus in the mouth. Clinical examination was always negative except for a "strange, smiling demeanour." remarked in previous case records. Acid values in the stomach, gastric cytology, gastroscopy, and routine barium meal, all previously performed, were reported negative. Furthermore. no abnormality had been found at three laparotomies in the past 15 years, and pyloroplasty and posterior gastrojejunostomy were performed at the second and third respectively.
A report on a further barium meal examination with cineradiography was: "The oesophagus showed a considerable amount of distension with air and a reflux of barium freely occurred into the oesophagus from the stomach. The gastroenterostomy functioned normally and there was no hold-up or delay to be seen. A remarkable reflux of barium into the oesophagus occurred, associated with a sliding type of hiatus hernia. This reflux appeared to be produced voluntarily by the patient. . . The vomiting of the daily quantity of fluid appears to be part of a rumination process. The patient was able to produce the appearances with barium while being watched on screen examination. He did not appear to be consciously aware of this phenomenon."

Anatomical differences apart, it would seem that the movements in the upper part of the stomach were akin to those in rumination in animals. The interest lies in the mechanism of production of these movements, in the associated oesophageal hiatus hernia, and the psychiatric inadequacy. It has been suggested that the bolus of food in the ruminator is propelled to the mouth by contraction of the upper part of the stomach, ${ }^{1}$ and that the raised intra-abdominal pressure induced by rumination weakens the anterior hiatal muscle, thus predisposing to the eventual development of an oesophageal hiatus hernia. ${ }^{2}$ There is no doubt that after a repair of his hiatus hernia there was a dramatic improvement in the patient's state with no further vomiting and a gain of 9.07 $\mathrm{kg}$ over three months. Cineradiography in the diagnosis of an unusual case is clearly important and the results obviate the need for one or more operations.-We are, etc.,

Royal Infirmary,

D. M. F. BATTY Edinburgh

Royal Hospital,

D. N. WILliams Sheffield

1 Long, C. F., American fournal of the Medical 2 Marchand, P., Thorax, 1957, 12, 189.

\section{The Queen's Shilling}

SIR,-I read with interest the report on the B.M.A.'s memorandum of evidence to the committee of inquiry into the armed Forces medical, dental, and nursing services (Supplement, 15 January, p. 15) and also your leading article, "The Queen's Shilling" (15 January, p. 126). I have recently voluntarily retired from the Navy and re-entered civilian practice.

I have always disagreed with the B.M.A.'s contention that integration of the three armed Forces medical services was undesirable. I appreciate that loyalties develop, but I am convinced that the real problem of recruitment lies in the need for a career structure which offers clinical scope and opportunity similar to N.H.S. practice. Promotion tied to rank often leads to promo tion out of the clinical field in which the doctor has chosen to practise. The service retiring age of 57 or 60 is a further disincentive. There is a need for avenues of entry at all levels of specialist training where vacancies exist, and the practice of demanding up to two years' notice of intention to retire or resign surely belongs to the dark ages. Salaries now paid to service medical officers are on the whole very satisfactory, and few permanent officers or their wives grumble much about frequent moves. What is lost is often gained by the enjoy- 